\title{
Interstitial Pneumonia Complicated by Sjögren's Syndrome, Hashimoto's Disease, Rheumatoid Arthritis and Primary Biliary Cirrhosis
}

\author{
Haruko Mryamoto *,***, Arata Azuma*, Yasuyuki Taniguchi*, Takuo TAKahashi*, \\ Akinobu Yoshimura*, Shinobu Hemmi***, Yuh FukUdA** and Shoji KudoH*
}

\begin{abstract}
A 66-year-old woman diagnosed as having Hashimoto's disease and rheumatoid arthritis manifested interstitial pneumonia. We diagnosed Sjögren's syndrome and primary biliary cirrhosis as complications in this case. Steroid therapy was relatively effective for the interstitial pneumonia which was in an active state; however, during tapering of the steroid, there was a relapse and also severe dry throat. Cyclophosphamide was added and was effective in the prevention of recurrence. Even after discontinuation of steroid therapy, her general condition is stabilized. It is very important to carefully investigate other organ involvement as a prognostic factor in cases in which there are multiple autoimmune diseases.
\end{abstract}

(Internal Medicine 39: 970-975, 2000)

Key words: overlap syndrome, immunosupressant

\section{Introduction}

Interstitial pneumonia is commonly accompanied by collagen vascular diseases. We treated a case, complicated by multiple autoimmune diseases, Sjögren's syndrome $(\mathrm{SjS})$, Hashimoto's disease, rheumatoid arthritis (RA) and primary biliary cirrhosis (PBC). In such cases, it is important to determine which autoimmune diseases are present and how to treat them.

We report here a patient with interstitial pneumonia accompanied by multiple collagen diseases which were well-controlled by treatment with a combination of steroid and cyclophosphamide.

\section{Case Report}

A 66-year-old Japanese woman who had been diagnosed with Hashimoto's disease at the age of 46 years and RA at the age of 63 years, had been taking nonsteroidal anti-inflammatory drugs (NSAID) and thyroid hormones and her symptoms were well controlled.

She was a homemaker and did not use tobacco or alcohol. In early May 1996, she developed a productive cough and was prescribed antibiotics at another hospital. Chest radiograph revealed bilateral interstitial pulmonary shadow which did not improve after treatment with antibiotics (Figs. 1,2). She was admitted to our hospital for further examination and treatment in early June 1996.

On admission, her body temperature was $36.3^{\circ} \mathrm{C}$. She had bilateral deformities and swelling of the proximal interphalangeal (PIP) and metacarpophalangeal (MIP) joints of her hands, but no apparent joint destruction. There was no clubbing. Thyroid gland and superficial lymph nodes were not palpable. Her frenulum linguae was short.

On auscultation, fine crackles were heard bilaterally in the lower back. Cardiac sounds were normal. Abdomen was soft and flat, and the liver and spleen were not palpable.

Laboratory data on admission are summarized in Table 1. Examination of blood cell count showed eosinophilia. Erythrocyte sedimation rate (ESR) was high.

Blood chemistry revealed liver dysfunction; lactate dehydrogenase (LDH), alkaline phosphatase (ALP), $\gamma$-glutamyl transpeptidase ( $\gamma$-GTP) values exceeded the upper limits. Serum concentration of anti-nuclear antibody (ANA), anti-DNA antibody, rheumatoid factor, and anti SS-A were slightly elevated. Anti-mitochondrial antibody (AMA) and its isozyme M2 were extremely high. Thyroid function studies revealed a low T3. Anti-thyroid and anti-microsome antibodies were high. We considered the possibility of the association of SjS and PBC based on these findings. She had never experienced dry eye

From *the Fourth Department of Internal Medicine, **the First Department of Pathology of Nippon Medical School, Tokyo and ***the Second Department of Internal Medicine, Hiroshima University School of Medicine, Hiroshima

Received for publication November 16,1999; Accepted for publication April 22, 2000

Reprint requests should be adressed to Dr. Haruko Miyamoto, the Fourth Department of Internal Medicine, Nippon Medical School, 1-1-5, Sendagi, Bunkyoku, Tokyo 113-8603 


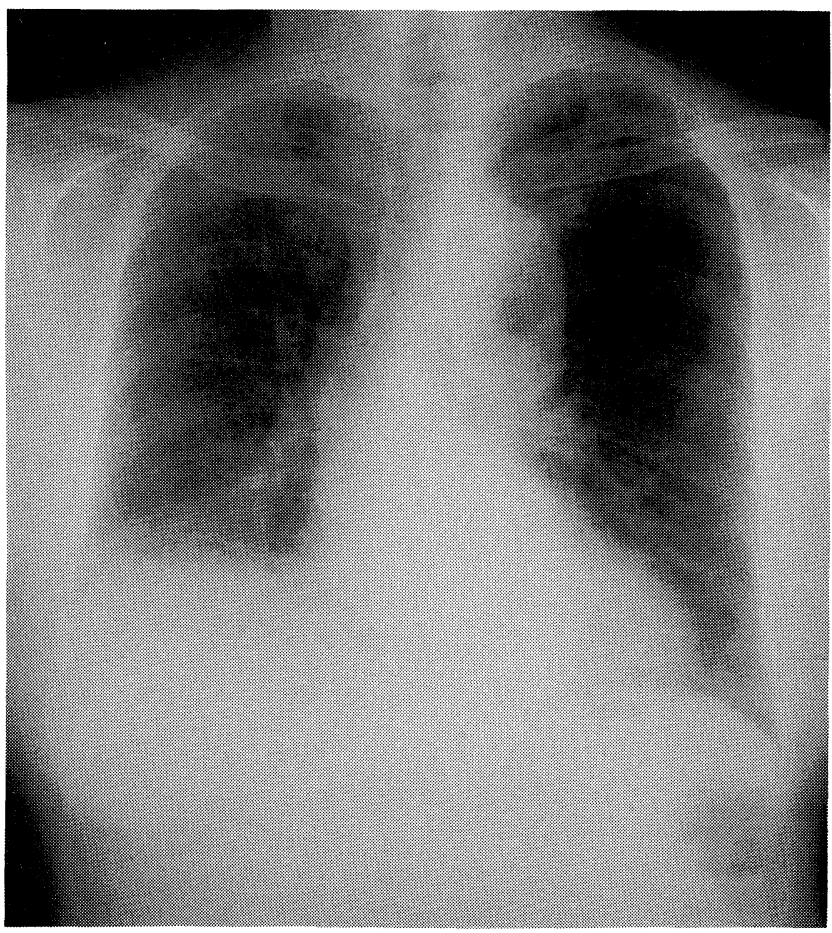

nor dry throat on admission, but both the Schirmir test and Rose bengal test were positive for keratoconjunctivitis. Sialography and lip biopsy showed findings of chronic sialoadenitis, consistent with the diagnosis of SjS (Fig. 3).

Liver biopsy revealed chronic non-suppurative destructive cholangitis (PBC stage I)(Fig. 4). Results of blood gas analysis were normal, but pulmonary function studies showed a mildly restrictive pattern and low diffusion capacity. Gallium (Ga) scintigram uptake was found in bilateral lungs. Examination of broncho-alveolar lavage fluid (BALF) showed a moderate elevation of lymphocytes, and the CD4/CD8 ratio was 0.53. The specimen from the transbronchial lung biopsy (TBLB) showed fibrosing- alveolitis with the mural incorporation type intraluminal fibrosis being dominant (nonspecific interstitial pneumonia pattern) (Fig. 5). We considered that the interstitial pneumonia was in an active state, and began treatment with $30 \mathrm{mg} /$ day of prednisolone for 4 weeks. We also began to use ursodeoxycholic acid (UDCA) for PBC. The in-

Figure 1. Chest radiograph on admissiom shows bilateral middle-lower ground glass shadow, more apparent in right lung.

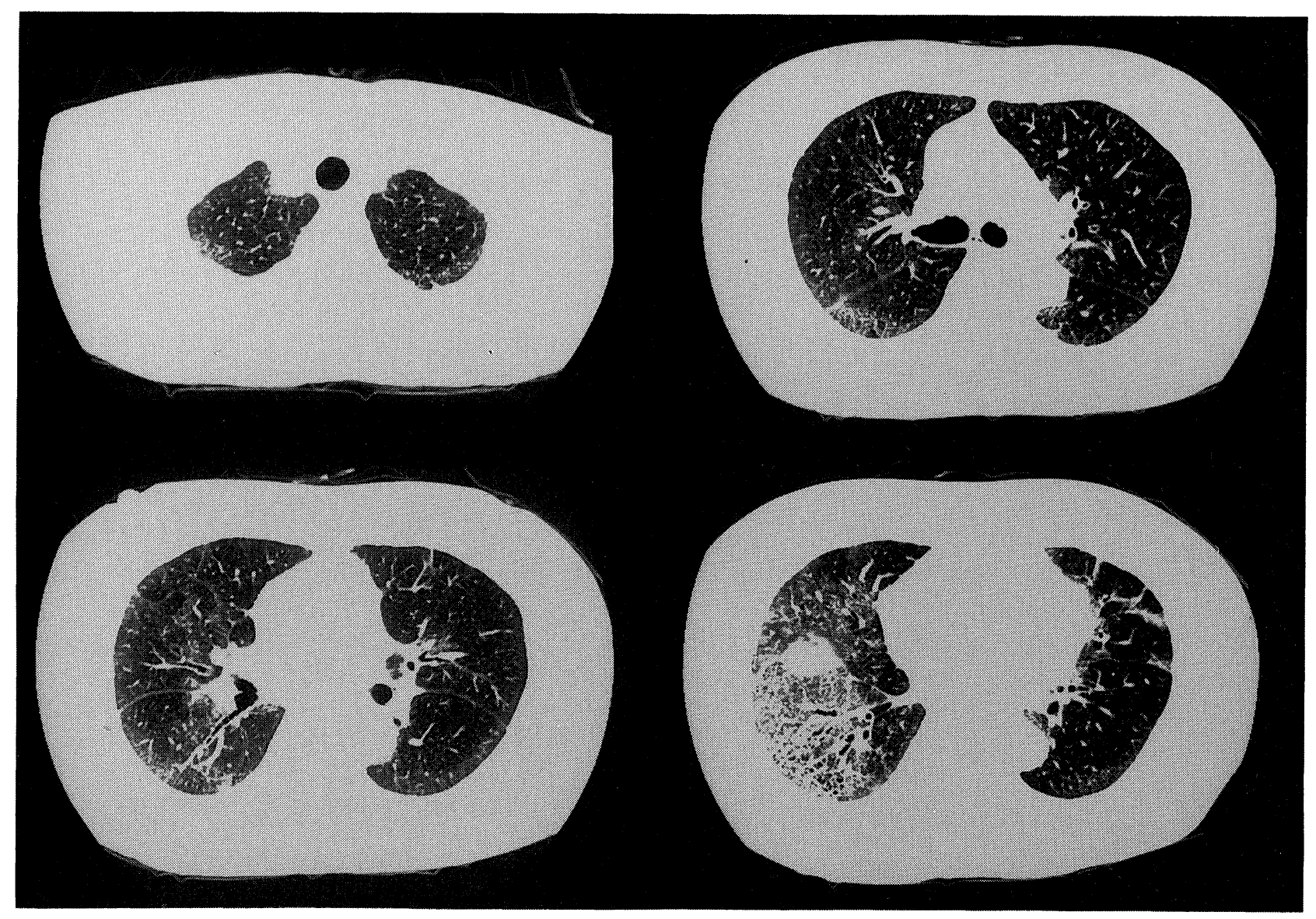

Figure 2. Chest high resolution computed tomography on admission shows bilateral interstitial shadow, mainly existed right lower back, right middle lobe, left lingular to lower lobe. Microcystic honeycomb pattern is involved. 
Table 1. Clinical Data On Admission

\begin{tabular}{|c|c|c|c|c|c|c|c|c|}
\hline \multicolumn{2}{|l|}{ Hematology } & \multicolumn{4}{|l|}{ Serology } & \multicolumn{3}{|c|}{ Pulmonary Function } \\
\hline White blood cells & $6,600 / \mu \mathrm{l}$ & \multicolumn{2}{|l|}{ CRP } & & $1.4 \mathrm{mg} / \mathrm{dl}$ & $\mathrm{VC}$ & \multicolumn{2}{|l|}{$1.74 \%$} \\
\hline Neutrophil & $41.0 \%$ & \multicolumn{2}{|l|}{$\underline{\operatorname{IgG}}$} & & $2,501.0 \mathrm{mg} / \mathrm{dl}$ & $\% \mathrm{VC}$ & \multicolumn{2}{|l|}{$73.4 \%$} \\
\hline Eosinophil & $15.9 \%$ & \multicolumn{2}{|l|}{ IgA } & & $320.0 \mathrm{mg} / \mathrm{dl}$ & $\mathrm{FEV}_{1.0}$ & \multicolumn{2}{|l|}{$1.33 l$} \\
\hline Basophil & $1.1 \%$ & \multicolumn{2}{|l|}{ IgM } & & $173.0 \mathrm{mg} / \mathrm{dl}$ & $\mathrm{FEV}_{1.0 \%}$ & \multicolumn{2}{|l|}{$80.6 \%$} \\
\hline Monocyte & $8.5 \%$ & \multicolumn{2}{|l|}{ IgE } & & $2,200.0 \mathrm{U} / \mathrm{ml}$ & $\%$ DLCO & \multicolumn{2}{|l|}{$69.6 \%$} \\
\hline Lymphocyte & $33.5 \%$ & \multicolumn{2}{|c|}{ ESR(1 hour/2 hour) } & & $30 / 71 \mathrm{~mm}$ & \multirow{2}{*}{\multicolumn{3}{|c|}{ Purified Protein Derivative }} \\
\hline Red blood cells & $397 \times 10^{4} / \mu 1$ & \multicolumn{2}{|c|}{ Cold Aggulutination } & & $128 x$ & & & \\
\hline $\mathrm{Hb}$ & $12.0 \mathrm{~g} / \mathrm{dl}$ & \multicolumn{2}{|c|}{ Mycoplasma Antibody } & & negative & $\underline{0 \times 0}$ & & \\
\hline Hematocrit & $35.6 \%$ & \multicolumn{2}{|c|}{ Anti Nuclear Antibody } & & $80 x$ & $5 \times 5$ & & \\
\hline \multirow[t]{2}{*}{ Platelet } & $22.3 \times 10^{4} / \mu 1$ & \multicolumn{3}{|c|}{ Anti Nuclear DNA antibody } & $160 x$ & & & \\
\hline & & \multicolumn{3}{|c|}{ anti-ss-DNA IgG } & $4 \mathrm{U} / \mathrm{ml}$ & Urinalysis & & \\
\hline Biochemistry & & \multicolumn{3}{|c|}{ anti-ds-DNA IgG } & $2 \mathrm{U} / \mathrm{ml}$ & W.N.L & & \\
\hline Alanine aminotransferase & $23 \mathrm{IU} / l$ & \multicolumn{3}{|c|}{ RF } & $86.3 \mathrm{IU} / \mathrm{ml}$ & & Right & Left \\
\hline Asparate aminotransferase & $29 \mathrm{IU} / l$ & \multicolumn{3}{|c|}{ anti-SS-A antibody } & $4 x$ & Schirmir Test & $0.5 \mathrm{~mm}$ & $1 \mathrm{~mm}$ \\
\hline LDH & $524 \mathrm{IU} / \mathrm{l}$ & \multicolumn{3}{|c|}{ anti-SS-B antibody } & negative & Rose Bengal Test & + & +++ \\
\hline ALP & $370 \mathrm{IU} / \mathrm{l}$ & \multicolumn{3}{|l|}{ LE test } & negative & & & \\
\hline$\gamma$-GTP & $91 \mathrm{IU} / l$ & \multicolumn{3}{|c|}{ anti-Scl antibody } & negative & & & \\
\hline Cholinesterase & $1,058 \mathrm{IU} / \mathrm{l}$ & anti-Jo-1 antib & & & negative & & & \\
\hline Total Bilirubin & $0.4 \mathrm{mg} / \mathrm{dl}$ & anti-Sm antibo & & & negative & & & \\
\hline Total cholesterol & $232 \mathrm{mg} / \mathrm{dl}$ & anti-RNP antil & & & negative & & & \\
\hline Triglyceride & $106 \mathrm{mg} / \mathrm{dl}$ & anti-smooth $\mathrm{m}$ & e anti & & negative & & & \\
\hline Creatine phosphokinase & $13 \mathrm{IU} / l$ & anti-mitochon & antib & & $640 x$ & & & \\
\hline Total Protein & $7.0 \mathrm{~g} / \mathrm{dl}$ & anti-mitochondr & 12 anti & & $196.9 \mathrm{U} / \mathrm{ml}$ & & & \\
\hline Albumin & $4.1 \mathrm{~g} / \mathrm{dl}$ & & & & & & & \\
\hline Blood Urea Nitrogen & $14 \mathrm{mg} / \mathrm{dl}$ & & & & & & & \\
\hline Creatinine & $0.7 \mathrm{mg} / \mathrm{dl}$ & Blood Gas Anal & (roon & & & & & \\
\hline $\mathrm{Na}$ & $136 \mathrm{mEq} / \mathrm{l}$ & $\mathrm{pH}$ & & & 7.406 & & & \\
\hline $\mathrm{K}$ & $3.7 \mathrm{mEq} / \mathrm{l}$ & $\mathrm{PaCO}_{2}$ & & & $40.3 \mathrm{mmHg}$ & & & \\
\hline $\mathrm{Cl}$ & $100 \mathrm{mEq} / \mathrm{l}$ & $\mathrm{PaO}_{2}$ & & & $81.7 \mathrm{mmHg}$ & & & \\
\hline Thyroid Function & & BAL & & & & & & \\
\hline FT3 & $2.4 \mathrm{pg} / \mathrm{ml}$ & Macrophage & 32 & 58 & 61 & & & \\
\hline FT4 & $1.0 \mathrm{ng} / \mathrm{dl}$ & Lymphocyte & 13 & 2 & 29 & & & \\
\hline TSH & $28.99 \mu \mathrm{U} / l$ & Neutrophil & 46 & 6 & 5 & & & \\
\hline $\begin{array}{l}\text { anti-thyroglobulin antibody } \\
\text { anti-microsome antibody }\end{array}$ & $\begin{array}{l}y \quad 640 x \\
400 x \\
\end{array}$ & Eosinophil & 9 & 8 & 5 & & & \\
\hline
\end{tabular}

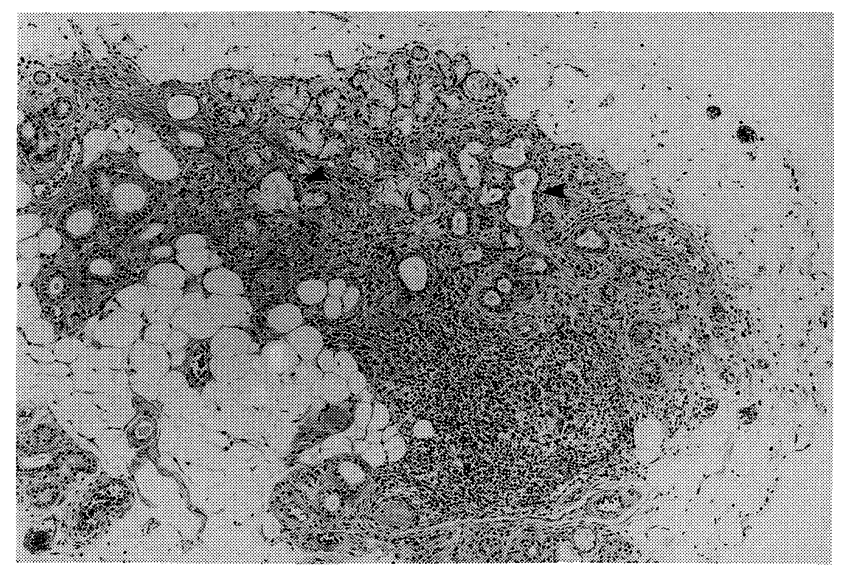

Figure 3. Lip biopsy specimen shows remarkable infiltration of lymphocytes and plasma cells with lymphatic follicles around the atrophic labial glands. Their ducts are dilated (arrowheads). These findings are compatible with chronic sialoadenitis (HE stain, $\times 250$ ).

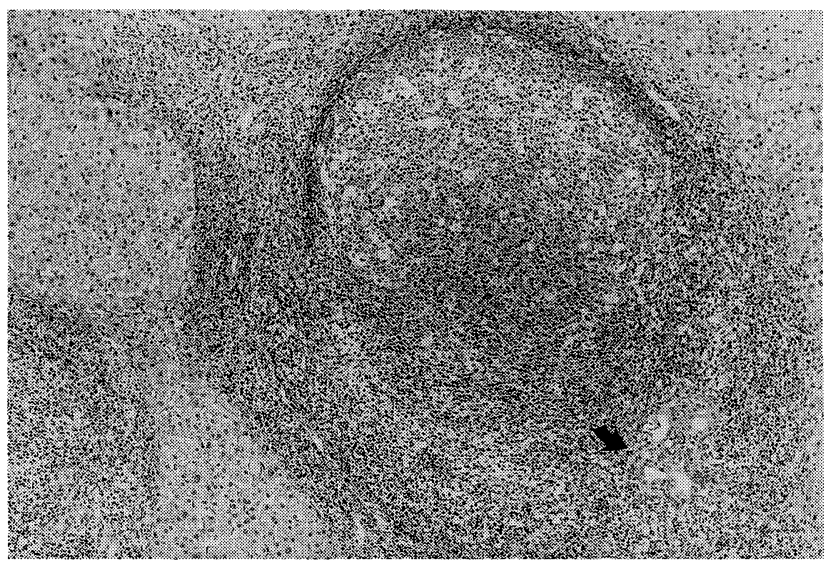

Figure 4. Liver biopsy specimen shows chronic non-suppurative destructive cholangitis. Lymphocytes infiltration with lymphatic follicles are observed around Glisson's capsule. Epithelial cells of intralobular ductules are swelling, accompanied with lymphocyte infiltration (arrow) (HE stain, $\times 250$ ). 
terstitial shadow of the bilateral lower lungs and swelling of her fingers joints gradually improved. But after tapering prednisolone by $5 \mathrm{mg}$ every 2 weeks, she began to complain of severe dry throat when the daily dose of prednisolone was reduced to $20 \mathrm{mg} / \mathrm{day}$. At the same time, $\mathrm{LDH}$ values elevated, in late August 1996.

Interstitial pulmonary shadows reappeared in late September. There were few respiratory symptoms at that time, but blood

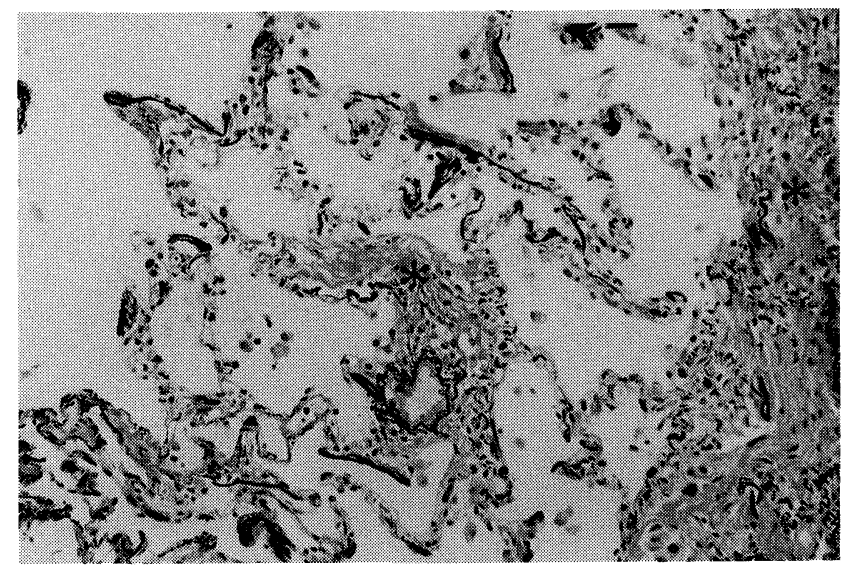

Figure 5. Transbronchial biopsy shows mural incorporationtype intraalveolar fibrosis $(*)$ with infiltration of lymphocytes (Elastica Masson Goldner stain, $\times 500)$. gas analysis showed deterioration of oxygenation. After $50 \mathrm{mg} /$ day of cyclophosphamide was added to $15 \mathrm{mg} /$ day of prednisolone, the interstitial pulmonary shadow improved gradually and pulmonary uptake of Ga scintigram decreased. Dry throat did not worsen further. Serum LDH and ESR values began to decline (Fig. 6). Serum ALP and $\gamma$-GTP levels normalized and AMA and antimitochondrial M2 antibody titer decreased (Table 2). Even during tapering of prednisolone, her general condition was stable. It has been almost 2 years since we discontinued prednisolone and continued the administration of $50 \mathrm{mg} / \mathrm{day}$ of cyclophosphamide. No side effects of cyclophosphamide have been observed up to date.

\section{Discussion}

This patient had been previously diagnosed as having Hashimoto's disease and RA at another hospital. We do not know if the interstitial pneumonia was present at that time. It is difficult to determine which of these autoimmune diseases resulted in the pulmonary manifestation. After admission to our hospital, definite diagnoses of $\mathrm{PBC}$ and $\mathrm{SjS}$ were made.

With regard to the interstitial pneumonia, we supposed that $\mathrm{RA}$ or $\mathrm{SjS}$ might have been responsible because pulmonary manifestations are frequent complications of these conditions $(1,2)$.

There have been some reports of interstitial pneumonia complicated by PBC or Hashimoto's disease without $\operatorname{SjS}(3,4)$, but the incidence is low. Rodriguez et al reported that pulmonary

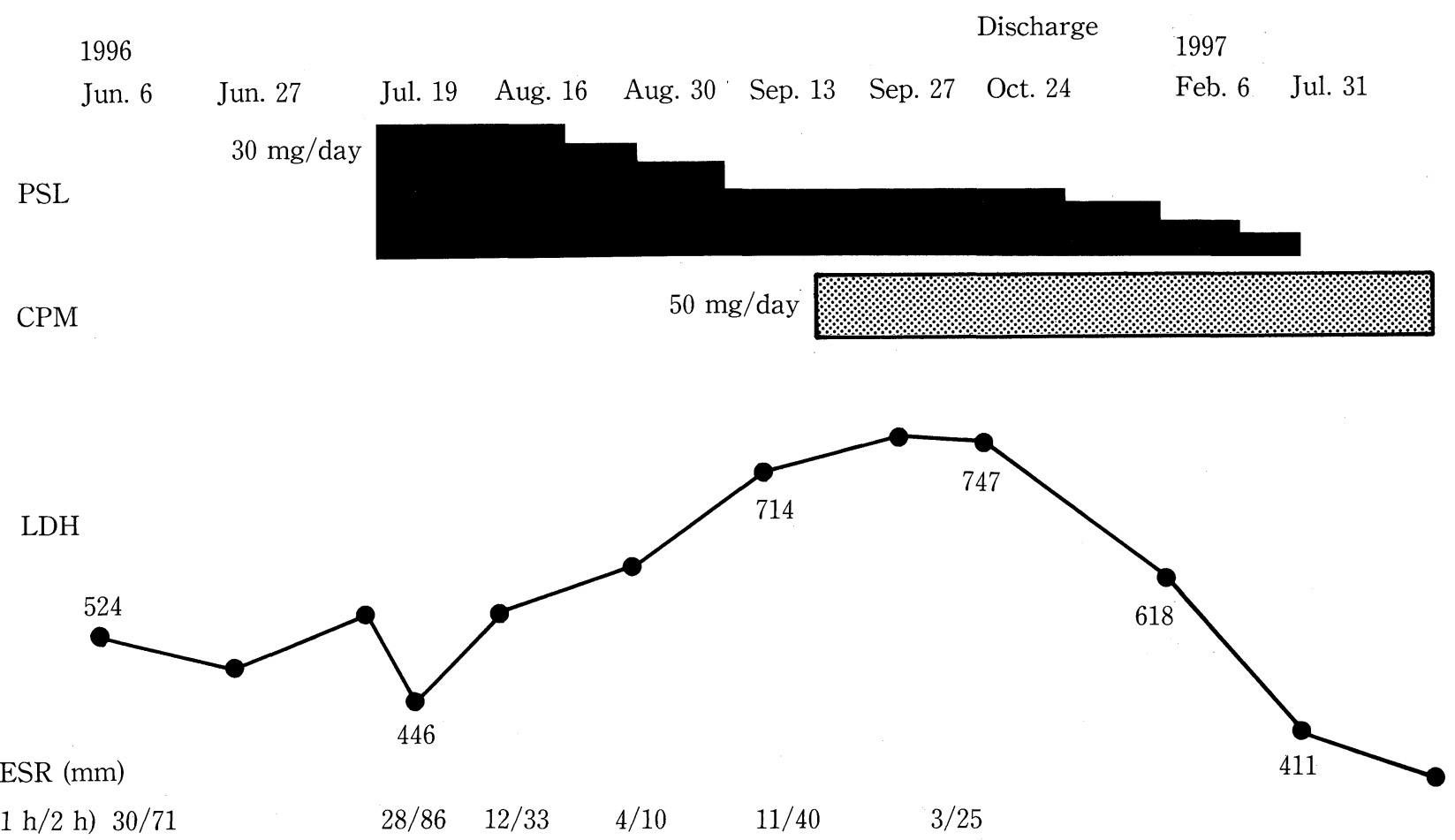

Figure 6. Clinical course of the patient. PSL: prednisolone, CPM: cyclophosphamide, ESR: erythrocyte sedimentation rate. 
MiYAmoto et al

Table 2. Liver Function and Antimitochondrial Antibody

\begin{tabular}{lrccc}
\hline & 96 & & & \\
& June 18 & August 1 & September 10 & October 10 \\
\hline AST (IU/l) & 23 & 13 & 20 & 19 \\
ALT (IU/l) & 29 & 15 & 18 & 17 \\
LDH (IU/l) & 524 & 538 & 722 & 731 \\
ALP (IU/l) & 370 & 268 & 178 & 183 \\
$\gamma$-GTP (IU/l) & 91 & 35 & 22 & 26 \\
Total Bilirubin & 0.4 & 0.5 & 0.4 & 0.5 \\
(mg/dl) & & & & 747 \\
Cholinesterase & 1,058 & 1,176 & 900 & \\
(IU/l) & & & & $320 \times$ \\
anti-mitochondrial antibody & $640 \times$ & $640 \times$ & $320 \times$ & 41.8 \\
anti-mitochondrial M2 antibody & 196.9 & 304.0 & 50.8 & \\
(U/ml) & & & & \\
\hline
\end{tabular}

involvement with $\mathrm{PBC}$ is the result of an associated connective tissue disorder, such as $\mathrm{SjS}$ rather than the PBC (5). We thought it is most appropriate to consider that all of these autoimmune diseases are present in association with $\mathrm{SjS}$. We can explain this case, complicated with multiple autoimmune diseases consistently as a secondary $\mathrm{SjS}$.

$\mathrm{SjS}$ is a chronic autoimmune disorder of the exocrine glands, frequently complicated by other autoimmune diseases. The prevalence of other collagen vascular diseases in association with $\mathrm{SjS}$ was reported to be $36.6 \%$ [RA $22.9 \%$, systemic lupus erythematosus $7.3 \%$, progressive systemic sclerosis $4.9 \%$, polymyositis/dermatomyositis $1.5 \%$ (6), according to the Ministry of Health and Welfare of Japan]. Chronic thyroiditis or Hashimoto's disease has been reported as the most frequent organ-specific autoimmune disease recognized in patients with $\mathrm{SjS}$ (7). Autoimmune thyroid diseases were found in 10-60\% of $\mathrm{SjS}(7,8)$. PBC has also been reported as one of the most frequent hepatic diseases associated with $\mathrm{SjS}$, its incidence ranges from 3-9\% (9). PBC has been proposed to be included in dry gland syndrome, caused by a disorder of exocrine grandular epithelial cells $(10,11)$. Dry eye and diminished secretion of pancreatic juice and bile are often observed in dry gland syndrome.

Wakabayashi et al reported a case of PBC associated with chronic thyroiditis and gastritis (12). Interstitial pneumonia was in an active state in the present case, because of moderate lymphocytosis in BALF, pulmonary uptake in Ga scintigram and subacute progression. Mural incorporation type of fibrosis was dominant in the TBLB specimen. Non-specific interstitial pneumonia (NSIP) pattern would be the most suitable explanation for this pathological feature. The rate of pulmonary involvement in $\mathrm{SjS}$ was reported to be $9 \%$ by Strimlan et al who studied 343 patients with a history of $\mathrm{SjS}$ (13). Constantopoulos et al reported that $75 \%$ of cases with primary $\mathrm{SjS}$ had evidence of pulmonary involvement (2). The rate varies depending on the study. Pulmonary involvement in the present patient may be associated with $\mathrm{SjS}$ and/or RA rather than Hashimoto's dis- ease or PBC. Pulmonary involvement can be detected at a relatively early stage with high resolution $\mathrm{CT}$, broncho-alveolar lavage (BAL), and pulmonary function testing (14).

In the present patient, steroid therapy was effective as the initial treatment. However, during the tapering of prednisolone, interstitial pneumonia relapsed. After adding cyclophosphamide, her general condition stabilized. With regard to PBC, after using prednisolone and UDCA, serum ALP and $\gamma$-GTP levels as well as AMA and anti-mitochondrial M2 antibody titers decreased. Liver function has also been stable after adding cyclophosphamide. Steroid and immunosupressant therapy should be reserved for patients with extraglandular involvement. Cyclophosphamide is a promising agent for the treatment of patients with unstable conditions despite the use of steroid therapy. We should carefully consider the association of any other autoimmune diseases, especially $\mathrm{SjS}$ when we examine patients with RA and Hashimoto's disease. We consider that the activity of interstitial pneumonia was one of the most important prognostic factors in this case.

In fact, pulmonary involvement determines the prognosis of those who have connective tissue diseases in more than a few cases (15). If various autoimmune diseases are present, we should take particular care especially in the event of relapse of interstitial pneumonia as well as manifestations of other autoimmune diseases.

It may be very important to further investigate pulmonary involvement as a prognostic factor in cases accompanied by multiple autoimmune diseases.

\section{References}

1) Schwalz MI. Pulmonary manifestations of the collagen vascular diseases. in: Fishman's Pulmonary Diseases and Disorders. 3rd ed. Fishman AP, Ed. McGraw-Hill, U.S.A, 1998: 1115-1132.

2) Constantopoulos SH, Papadimitriou CS, Moutsopoulos HM. Respiratory manifestations in primary Sjögren's syndrome. A Clinical, Functional, and Histologic Study. Chest 88: 226-229, 1985.

3) Weissman E, Becker NH. Interstitial lung disease in primary biliary cir- 


\section{Interstitial Pneumonia with SjS, Hashimoto Disease, RA and PBC}

rhosis. Am J Med Sci 285: 21-27, 1983.

4) Yamaguchi K, Kato N. An autopsy case of diffuse interstitial pulmonary fibrosis associated with Hashimoto's thyroiditis. Nippon Naika Gakkai Zasshi. 63: 1428-1435, 1974 (in Japanese).

5) Rodriguez-Roisin R, Pares A, Bruguera $M$, et al. Pulmonary involvement in primary biliary cirrhosis. Thorax 36: 208-212, 1981.

6) Tojo T, Ofuji T, Miyawaki S. The Epidemiological survey on Sjögren's disease in Japan I. Preliminary Report in Annual Report of the Ministry of Health and Welfare Sjögren's Disease Research Commitee, Japan, 1978: 45-61.

7) Ichikawa Y, Fukuda R. Clinical and pathological features of Sjögren's syndrome associated with autoimmune thyroid diseases. Nippon Rinsho 53: 2545-2550, 1995 (in Japanese, Abstract in English).

8) Perez-E B, Kraus A, Lopez G, Cifuentes M, Alarcon-Segovia D. Autoimmune thyroid disease in primary Sjögren's syndrome. Am J Med 99: 480 484, 1995.

9) Furuya T, Tateishi M, Nishinarita M, Kashiwazaki S. Primary biliary cir- rhosis in patients with Sjögren's syndrome. Nippon Rinsho 53: 25362539, 1995 (in Japanese, Abstract in English).

10) Macgregor GA. PBC is a dry-gland syndrome. Lancet 2: 535, 1980 (letter).

11) Shanahan F, Stack J, Maguire S, Crowe J. The pancreas, primary biliary cirrhosis and the dry gland syndrome. Ir J Med Sci 154: 387-389, 1985

12) Wakabayashi $T$, Ohno H, Hayakawa $Y$, Kawashima A, Sawabu N. Primary biliary cirrhosis associated with type A gastritis and chronic thyroiditis. J Gastroenterol 34: 415-419, 1999.

13) Strimlan CV, Rosenow EC, Divertie MB, Harrison EG Jr. Pulmonary manifestations of Sjögren's syndrome. Chest 70: 354-361, 1976.

14) Papathanasiou MP, Constantopoulos SH, Tsampoulas C, Drosos AA, Moutsopoulos HM. Reappraisal of respiratory abnormalities in primary and secondary Sjögren's syndrome. Chest 90: 370-374, 1986.

15) Hirakata $M$, Nakamura $K$, Kaburaki J, et al. Interstitial lung disease in patients with connective tissue diseases. Nippon Kyobu Shikkan Gakkai Zasshi 33 Suppl: 268-276, 1995 (in Japanese, Abstract in English). 